\title{
ORCHIDEE-CROP (v0), a new process-based agro-land surface model: model description and evaluation over Europe
}

\author{
X. Wu ${ }^{1,2}$, N. Vuichard ${ }^{1}$, P. Ciais ${ }^{1}$, N. Viovy ${ }^{1}$, N. de Noblet-Ducoudré ${ }^{1}$, X. Wang ${ }^{3}$, V. Magliulo ${ }^{4}$, M. Wattenbach ${ }^{5}$, \\ L. Vitale ${ }^{4}$, P. Di Tommasi ${ }^{4}$, E. J. Moors ${ }^{6}$, W. Jans ${ }^{6}$, J. Elbers ${ }^{6}$, E. Ceschia ${ }^{7}$, T. Tallec ${ }^{7}$, C. Bernhofer ${ }^{8}$, T. Grünwald ${ }^{8}$, \\ C. Moureaux ${ }^{9}$, T. Manise ${ }^{9}$, A. Ligne ${ }^{9}$, P. Cellier ${ }^{10}$, B. Loubet ${ }^{10}$, E. Larmanou ${ }^{10}$, and D. Ripoche ${ }^{11}$ \\ ${ }^{1}$ CEA-CNRS-UVSQ, UMR8212-Laboratoire des Sciences du Climat et de l'Environnement (LSCE), Orme des Merisiers, \\ 91191 Gif-Sur-Yvette, France \\ ${ }^{2}$ College of Resources Science and Technology, Beijing Normal University, Beijing 100875, China \\ ${ }^{3}$ Sino-French Institute for Earth System Science, College of Urban and Environmental Sciences, Peking University, \\ Beijing 100871, China \\ ${ }^{4}$ Istituto per i Sistemi Agricoli e Forestali del Mediterraneo, CNR, Via C. Patacca 85, 80056 Ercolano (Napoli), Italy \\ ${ }^{5}$ Helmholtz Centre Potsdam GFZ German Research Centre For Geosciences, Deutsches GeoForschungsZentrum GFZ, \\ Telegrafenberg, 14473 Potsdam, Germany \\ ${ }^{6}$ Wageningen UR, Alterra, Earth System Science and Climate Change Group, P.O. Box 47, 6700 AA Wageningen, \\ the Netherlands \\ ${ }^{7}$ CESBIO, UMR5126 - CNES-CNRS-UPS-IRD - 18 avenue Edouard Belin 31401 Toulouse CEDEX 9, France \\ ${ }^{8}$ Technische Universität Dresden, Institute of Hydrology and Meteorology, Pienner Str. 23, 01737 Tharandt, Germany \\ ${ }^{9}$ Université de Liège - Gembloux Agro-Bio Tech, Crops Management Unit, 5030 Gembloux, Belgium \\ ${ }^{10}$ INRA, UMR INRA-AgroParisTech ECOSYS (Ecologie fonctionnelle et écotoxicologie des agro-écosystèmes), \\ 78850 Thiverval-Grignon, France \\ ${ }^{11}$ INRA, US1116 AgroClim, Avignon, France
}

Correspondence to: X. Wu (xiuchen.wu@bnu.edu.cn) and N. Vuichard (nicolas.vuichard@1sce.ipsl.fr)

Received: 4 April 2015 - Published in Geosci. Model Dev. Discuss.: 22 June 2015

Revised: 27 December 2015 - Accepted: 11 January 2016 - Published: 1 March 2016

\begin{abstract}
The response of crops to changing climate and atmospheric $\mathrm{CO}_{2}$ concentration $\left(\left[\mathrm{CO}_{2}\right]\right)$ could have large effects on food production, and impact carbon, water, and energy fluxes, causing feedbacks to the climate. To simulate the response of temperate crops to changing climate and $\left[\mathrm{CO}_{2}\right]$, which accounts for the specific phenology of crops mediated by management practice, we describe here the development of a process-oriented terrestrial biogeochemical model named ORCHIDEE-CROP (v0), which integrates a generic crop phenology and harvest module, and a very simple parameterization of nitrogen fertilization, into the land surface model (LSM) ORCHIDEEv196, in order to simulate biophysical and biochemical interactions in croplands, as well as plant productivity and harvested yield. The model is applicable for a range of temperate crops, but is tested here using maize and winter wheat, with the phenological parameteriza-
\end{abstract}

tions of two European varieties originating from the STICS agronomical model. We evaluate the ORCHIDEE-CROP (v0) model against eddy covariance and biometric measurements at seven winter wheat and maize sites in Europe. The specific ecosystem variables used in the evaluation are $\mathrm{CO}_{2}$ fluxes (net ecosystem exchange, NEE), latent heat, and sensible heat fluxes. Additional measurements of leaf area index (LAI) and aboveground biomass and yield are used as well. Evaluation results revealed that ORCHIDEE-CROP (v0) reproduced the observed timing of crop development stages and the amplitude of the LAI changes. This is in contrast to ORCHIDEEv196 where, by default, crops have the same phenology as grass. A halving of the root mean square error for LAI from $2.38 \pm 0.77$ to $1.08 \pm 0.34 \mathrm{~m}^{2} \mathrm{~m}^{-2}$ was obtained when ORCHIDEEv196 and ORCHIDEE-CROP (v0) were compared across the seven study sites. Improved crop 
phenology and carbon allocation led to a good match between modeled and observed aboveground biomass (with a normalized root mean squared error (NRMSE) of 11.0$54.2 \%$ ), crop yield, daily carbon and energy fluxes (with a NRMSE of $\sim 9.0-20.1$ and $\sim 9.4-22.3 \%$ for NEE), and sensible and latent heat fluxes. The simulated yields for winter wheat and maize from ORCHIDEE-CROP (v0) showed a good match with the simulated results from STICS for three sites with available crop yield observations, where the average NRMSE was $\sim 8.8 \%$. The model data misfit for energy fluxes were within the uncertainties of the measurements, which themselves showed an incomplete energy balance closure within the range $80.6-86.3 \%$. The remaining discrepancies between the modeled and observed LAI and other variables at specific sites were partly attributable to unrealistic representations of management events by the model. ORCHIDEE-CROP (v0) has the ability to capture the spatial gradients of carbon and energy-related variables, such as gross primary productivity, NEE, and sensible and latent heat fluxes across the sites in Europe, which is an important requirement for future spatially explicit simulations. Further improvement of the model, with an explicit parameterization of nutritional dynamics and management, is expected to improve its predictive ability to simulate croplands in an Earth system model.

\section{Introduction}

Croplands cover about $12 \%$ of the world land surface (Ramankutty and Foley, 1998), with temporal and spatial variations being subject to population increase, changes in diet, market prices, and other socio-economic factors (IPCC, 2014; Ramankutty et al., 2002; Vuichard et al., 2008). The response of croplands to climate change is expected to have significant, but uncertain, consequences for (1) global food production and (2) land surface water, carbon, and energy fluxes, which affect food security as well as regional climate and water resources (Bonan, 2008, 2001; Loarie et al., 2011; Rosenzweig et al., 2014).

Along with improving understanding of crop physiology to increase production and yield quality, research has focused on investigating the climate impacts on crop functioning by combining historical observations with statistical models (Lobell and Field, 2007; Lobell et al., 2011; Rosenzweig and Parry, 1994) or by running crop models from site to global scales. Impact studies have always pointed to the significant effect of climate on crop yield variability (Lobell and Field, 2007; Parry et al., 2005; Rosenzweig et al., 2014). However, discrepancies in the response to climate change between different crop models have highlighted the uncertainties that are related to model structure, parameterization, and external drivers (Asseng et al., 2013; Müller, 2011; Rosenzweig et al., 2014).
There is an increasing need to improve understanding of the environmental and climate consequences of changes in cropland area and in management practices, via modification of biophysical and biogeochemical land-atmosphere fluxes (Foley et al., 2011; Lobell et al., 2006; Osborne et al., 2009; Tubiello et al., 2007). Many lines of evidence show that changes of cropland plant properties can strongly modify the biophysical characteristics (albedo, roughness, turbulent fluxes) of the land surface, which affect local and regional climates (Davin et al., 2014; Foley et al., 2011; Georgescu et al., 2009; Loarie et al., 2011; Osborne et al., 2009).

Investigation of cropland-climate interactions has led to new model developments that improve land surface models (LSMs) so that they give a more realistic representation of crop processes (Bondeau et al., 2007; Gervois et al., 2004; Kucharik, 2003). The aim is to simulate the spatial distribution and variability of crop production and its water, energy, and carbon fluxes, all of which affect climate. These efforts have improved the seasonal dynamics of modeled foliar and biomass developments (Bondeau et al., 2007; Gervois et al., 2008, 2004; Kucharik, 2003; Valade et al., 2014; Van den Hoof et al., 2011) and long-term soil carbon changes (Ciais et al., 2011). Despite progress, these AgroLSM models have some limitations, such as (1) static or crop-/region-specific parameterizations (Berg et al., 2011; Kucharik, 2003), (2) idealized representation of different crop types and cultivation practices (Bondeau et al., 2007), and (3) incomplete coupling between crop growth parameterizations and LSM processes (de Noblet-Ducoudré et al., 2004; Gervois et al., 2004; Valade et al., 2014).

In this study, we integrate a generic crop phenology and allocation module from the STICS agronomical model, which has been extensively validated and can simulate different crops (e.g., wheat, maize, soybean, bananas) (Brisson et al., 1998, 2002) into the carbon-water-energy LSM ORCHIDEE model (Krinner et al., 2005), resulting in a new agro-land surface model, ORCHIDEE-CROP (at version v0; hereafter referred to as ORCHIDEE-CROP; https://forge.ipsl.jussieu.fr/orchidee/ wiki/DevelopmentActivities). ORCHIDEE-CROP has two applications: offline and online. Offline applications (presented here) improve understanding of the mechanisms controlling yield, given climate and management forcing. Online simulations require the crop model to be coupled with an atmospheric model (GCM) when studying crop vegetation feedbacks on climate. Several crop models have been developed for offline applications and impact studies, but very few of these models can be coupled with GCMs, e.g., because they do not represent albedo, roughness, and sensible and latent heat fluxes on the typical time step of $\approx 30 \mathrm{~min}$, which are required to couple with a GCM.

Our efforts have focused on improving the representation of phenology, the simulation of biophysical and biogeochemical fluxes, and on biomass and grain yields. ORCHIDEE- 
CROP can solve the incomplete coupling problems in the existing ORCHIDEE-STICS model (Gervois et al., 2004).

We first describe the structure of ORCHIDEE-CROP (Sect. 2) and evaluate the new model for phenology, $\mathrm{CO}_{2}$, and energy fluxes over winter wheat and maize sites across a large climate gradient in Europe using observations of biophysical and carbon variables (LAI, biomass, latent (LE) and sensible heat $(\mathrm{H})$ fluxes, and net ecosystem exchange (NEE)) from seven eddy covariance sites (Sect. 3). Finally, we discuss the general performance of ORCHIDEE-CROP, its limitations, and the future research that is needed (Sect. 4).

\section{Materials and methods}

\subsection{Model description}

Two key processes of crop plants were introduced into a module integrated in ORCHIDEEv196 (version Tag196; http://forge.ipsl.jussieu.fr/orchidee/wiki/Tags/196; called ORCHIDEE hereafter). This module simulates crop phenology and the specific carbon allocation to grain prior to harvest (Fig. 1). This crop module is used to calculate (1) the seasonal dynamics of LAI, a key variable that impacts surface biophysical properties (albedo, roughness) and water, energy and carbon fluxes, and (2) the timing and amount of grain filling that determines yield.

In ORCHIDEE, the vegetation is divided into 13 plant function types (PFTs), including bare soil, 10 natural PFTs (e.g., evergreen and deciduous trees, C3, and C4 grass) and two crop PFTs (C3 and C4 crops) that are assumed to have the same phenology as natural grasslands, but with higher carboxylation rates (Krinner et al., 2005). More vegetation types can be simulated using a new PFT external definition module (http://labex.ipsl.fr/orchidee/index. php/about-orchidee). Several PFTs can coexist within the same grid cell (also referred to as mosaic vegetation), which can have any size, generally given by the spatial resolution of climate forcing data. All PFTs that co-exist within a grid cell share the same climate forcing but different carbon, energy, and water dynamics, due to their specific parameterizations. The sum of fluxes from the different PFT tiles is averaged before being entered into the atmospheric model, in order to avoid coupled simulations.

\subsubsection{Crop development stages and phenology in ORCHIDEE-CROP}

A thermal index (degree day) adjusted for photoperiodic and vernalization effects according to crop types, controls the developments of temperate crops, such as winter wheat and maize considered here. Seven development stages are sequentially simulated for crop growth and grain filling in the crop module, which is the same as the processes in STICS (Fig. 1 in Brisson et al., 1998). The timing and duration of each stage is calculated based on development units, which describe the physiological requirements of crops. These development units are calculated, as in STICS, as growing degree days weighted by limiting functions to account for photoperiodism (e.g., winter wheat and soybean) and vernalization (e.g., winter wheat). Vernalization requirement is defined as a given number of vernalizing days (JVC) since the crop germination, and requires a minimum of 7 vernalizing days. The vernalizing value of a given day (JVI) is a function of air temperature. The vernalization status (RFVI) of the vernalization sensitive crop increases gradually to one when the vernalization requirement is met (Eq. S1 in the Supplement). The photoperiodic slowing effect, RFPI, is determined by two photoperiod thresholds, PHOBASE and PHOSAT, for photoperiodic crops. In the case of short-day crops, the PHOBASE is higher than PHOSAT, whereas in the case of long-day crops, the PHOBASE is lower than PHOSAT. The current photoperiod PHOI is calculated on the basis of calendar days and latitude (Sellers, 1965) (Eq. S2). Transition between stages occurs when the threshold values of development units are reached, which are specific to different crops or cultivars, but also depend upon management intensity and local climate. Using generic terms for the various plant development stages makes it possible to simulate different kinds of crops if crop-specific parameter values are provided (Bassu et al., 2014; Brisson et al., 2002; Valade et al., 2014).

Crop emergence occurs during the sowing-emergence stage, and is divided into seed germination and epicotyl extension. Germination occurs when the sum of degree days, using the soil temperature (TSOL) at the sowing depth (PROFSEM), reaches a given threshold (STPLTGER) and is dependent on soil dryness (Eq. S3). The growth rate of the epicotyl is assumed to be a logistic function that depends on soil temperature and water status at the sowing depth (Eq. S4). Crop emergence occurs when the epicotyl elongates and is dependent on planting depth (PROFSEM). The actual density of emerged plants is calculated from the initial sowing density, a fixed parameter, which takes into account some lack of germination and the death of a fraction of young plants due to unsuitable soil moisture (humectation or drought) and/or to thermal time deficit (Brisson et al., 2008). During this stage, extremely cold temperatures can reduce the seedling density through its effects on both vernalization and thermal limits for cold-sensitive crops (e.g., winter wheat). From emergence to physiological maturity, the temporal evolution of LAI is calculated in the crop module as the net balance between leaf growth and senescence. The daily growth rate of LAI (DELTAI) is calculated based on a logistic function of development units $\left(\mathrm{DELTAI}_{\mathrm{dev}}\right.$, related to different development stages) multiplied by an effective crop temperature, an effective plant density, which takes the inter-plant competition into account, and stress functions $\left(\right.$ DELTAI $\left._{\text {stress }}\right)$ related to water and nitrogen limitations (Eq. S5) (Brisson et al., 1998). The leaf senescence depends upon the evolution of temperature and leaf lifespan as a 


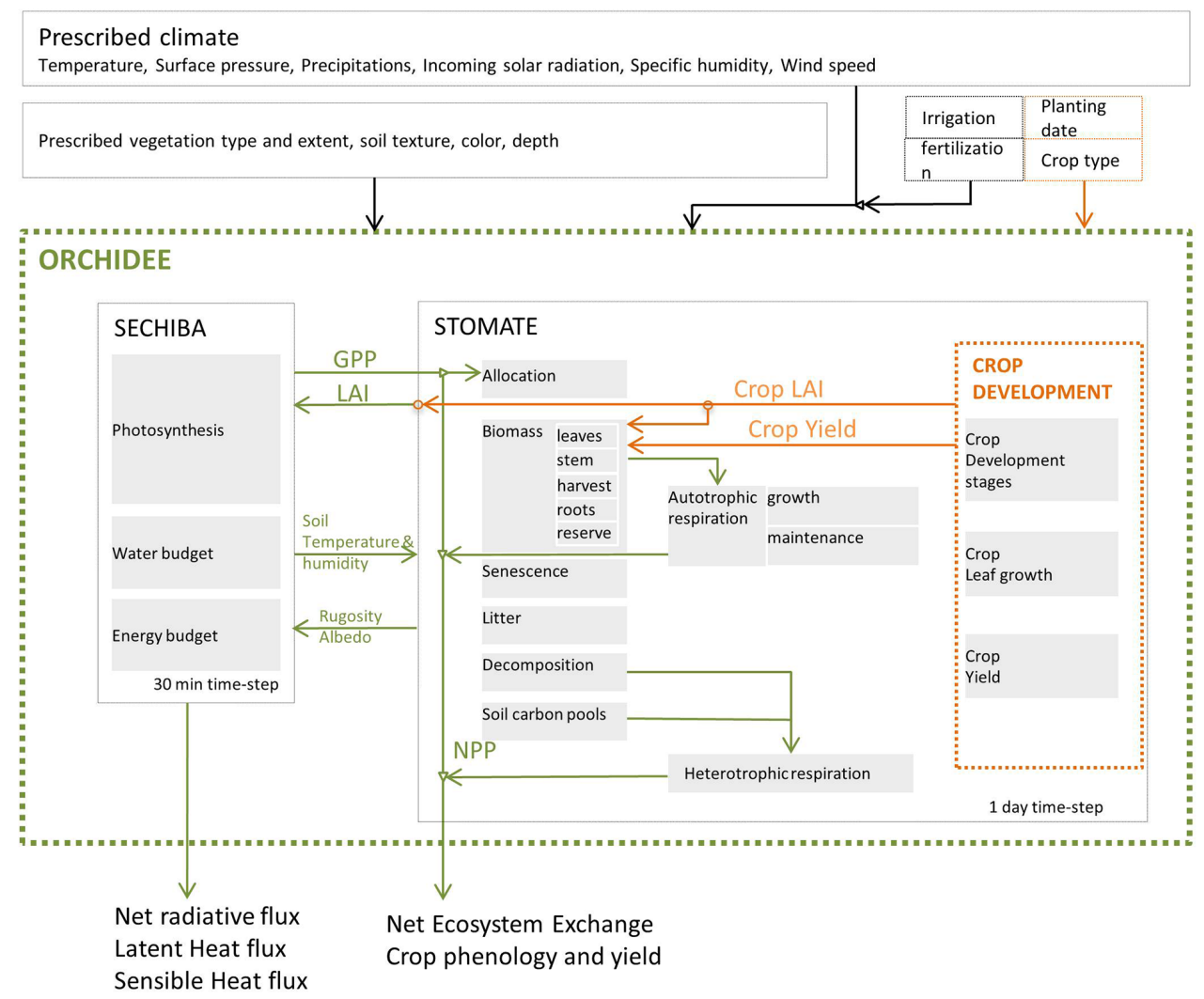

Figure 1. Model structures of the ORCHIDEE-CROP. The crop development module (based mainly on STICS; Brisson et al., 1998) is integrated into the STOMATE module of ORCHIDEE (Krinner et al., 2005). The crop development module simulated the phenology, developments, and grain yields for crop PFTs. ORCHIDEE-CROP consists in the coupling of two modules. SECHIBA simulates the vegetation photosynthesis, water, and energy budgets; STOMATE is a carbon module and calculates carbon allocation in different carbon pools and fluxes to the atmosphere. This figure is adapted from Valade et al. (2014).

function of leaf development and stresses (e.g., water stress). Consequently, leaf senescence is updated each day (Brisson et al., 2008). Extremely hot and/or cold temperatures from crop emergence to maturity can affect leaf dynamics through its effects on both the daily leaf growth increment and leaf senescence of crops, and thus significantly affects photosynthesis and carbon allocations.

\subsubsection{Photosynthesis, carbon allocation, and yield}

In ORCHIDEE-CROP, photosynthesis is calculated using ORCHIDEE (Krinner et al., 2005), which is based on the Farquhar leaf photosynthesis model for $\mathrm{C} 3$ crops (Farquhar et al., 1980) and on the model developed by Collatz et al. (1992) for C4 crops. In both cases, photosynthetic rate is the minimum of the Rubisco-limited rate for $\mathrm{CO}_{2}$ assimilation and the electron transport-limited rate for $\mathrm{CO}_{2}$ assimilation, whose maximal values are the model parameters $V_{\text {cmax }}$ and $V_{\text {jmax }}$, respectively. These two parameters can be calibrated using, for instance, the leaf-level measurements for different kinds of crops and varieties.
In ORCHIDEE, the carbon allocation model common to all PFTs is adapted from Friedlingstein et al. (1999) and accounts for eight biomass compartments (leaves, roots, fruits/harvested organs, reserves, aboveground sapwood, belowground sapwood, aboveground heartwood, and belowground heartwood) for trees, and considers five carbon pools for grass and crop PFTs (leaves, roots, fruits/harvested organs, reserves, and aboveground sapwood). The fractions of newly formed assimilates or reserves allocated to these pools are parameterized as a function of soil water content, temperature, light, and soil nitrogen availability.

In ORCHIDEE-CROP, we modified the carbon allocation scheme of the two crop PFTs to reconcile the calculations for leaf and root biomass and grain yield (fruits/harvested organs), which are driven by the phenology and LAI development parameterizations described in Sect. 2.1.1. Specifically, the daily increment of leaf biomass for crops, $\Delta_{\text {leaf_m }}$, is calculated by dividing the daily change in LAI, $\Delta_{\text {LAI }}$, by specific leaf area (sla), which is weighted by the water and nitrogen stress factors (Brisson et al., 2008) as given by 
$\Delta_{\text {leaf_m }}=\Delta_{\text {LAI }} /$ sla.

The daily increment for root biomass is determined by the daily total biomass increment and a daily dynamic belowground-to-total biomass partition coefficient, which depends on root development through a normalized root development unit. After the start of the grain filling stage, the dry matter accumulation in grains is calculated using a harvest index function that determines the daily fraction of the increment for the total biomass allocated to grain filling. This harvest index function increases linearly with time from the start of grain filling to the physiological maturity of the crop (when crop is harvested), and is restricted by an upper limit. The effects of extreme temperature on the grain filling process are described in Eq. (S6) (Brisson et al., 2008). The remaining daily net primary production (NPP), once allocation to leaf, root, and grain biomass is performed (the latter occurring only after the start of the grain filling phase), is allocated to the stem compartment to conserve mass. This residual stem compartment denotes both the actual stem biomass and additional reserves. At harvest, a small part of the carbon (with the same amount allotted to planted seeds) is moved from harvested organs to the reserves pool. This mimics the amount of carbon that seeds need for the next crop season.

In ORCHIDEE-CROP, the carbon allocation priority to different compartments was changed so that it was consistent with the growth development phases derived from STICS. In the vegetative stages, the leaf and root have the highest priority. If the NPP supply cannot satisfy the leaf and root biomass demand, no carbon is allocated to stems and the required amount of carbon demanded for leaf and root growth is removed from the reserves. If the extreme case occurs, in which the reserves are not sufficient, the amount of NPP allocated to leaf and root is reduced in proportion to the shoot/root ratio (no carbon being allocated to the stem). However, in such extreme cases, the consistency between LAI and leaf biomass is lost. Conversely, during the reproductive stage, carbon allocation is prioritized to grain filling and leaf biomass, followed by stem and root allocation of the remaining NPP. If the NPP available after satisfying the grain demand is not sufficient to support the allocation to the leaf, then carbon is remobilized from stem and root according to a fixed shoot/ root ratio.

\subsubsection{Soil moisture limitation effect on plant growth}

Water limitation for crop development and biomass production is accounted for through a water stress index calculated from ORCHIDEE, and ranges from 0 to 1 . It allows for reduced leaf growth and accelerated leaf senescence rates. The root water uptake function in ORCHIDEE is based on the assumption that the vertical root density distribution exponentially decreases with depth (Krinner et al., 2005) and that water uptake is a function of root zone extractable water weighted by the root profile. Relative water content in the root zone is an index defined by the difference between actual water content and the wilting point, divided by the difference between field capacity and the wilting point. This index always varies between 0 and 1 . Below a fixed relative root zone water content threshold of 0.5 , the ORCHIDEE stress index value decreases from 1 (no stress) to zero (wilting point). This stress index is used as a multiplier for both $V_{\text {cmax }}$ and stomatal conductance, and leads to a decrease in gross primary productivity and transpiration.

Two different soil hydrological schemes, namely a twolayer soil scheme, referred to as 2LAY, and an 11 layer soil diffusion scheme, referred to as 11LAY (Guimberteau et al., 2014) were used in this study to calculate soil moisture and all dependent ecosystem state variables. In ORCHIDEECROP (V0), soil hydrology is simulated for three separate soil tiles in each grid cell. These three tiles are covered by bare soil, short vegetation (including crops), and by forest vegetation. Here, for site-scale simulations, we assumed a grid cell with single tile entirely covered by crops.

Relative root extractable soil moisture in the different soil layers was computed in each hydrological scheme as the mean relative soil moisture over the different soil layers, weighted by the fraction of roots within each layer (Krinner et al., 2005). The stress index defined above was then calculated based on relative root extractable water, which differs between the $2 \mathrm{LAY}$ and the 11LAY versions. Irrigation was not taken into account in the current version of ORCHIDEECROP. The typical exponential (static) root profile assumed for grass and crop PFT in ORCHIDEE locates $\sim 65 \%$ of the roots in the upper $20 \mathrm{~cm}$ of the soil. This root distribution profile was different from the one that was used in STICS, where fewer roots were assumed to be in the upper $20 \mathrm{~cm}$ of soil and more below (Brisson et al., 2008; Gervois et al., 2004). In ORCHIDEE-CROP we kept the root profile as parameterized in ORCHIDEE.

\subsubsection{Simplified nitrogen limitation and fertilization effects}

Nitrogen fertilization increases crop productivity and the LAI, which consequently impacts on crop phenology, carbon allocation, and turbulent fluxes exchanged with the atmosphere (Mueller et al., 2012). ORCHIDEE-CROP is currently unable to account for dynamic nitrogen stress within the crop growing season due to the lack of an explicit parameterization of nitrogen processes and nitrogen-carbon interactions. We thus defined a simple nitrogen limitation index (innlai) and expressed it as a parameter ranging from 0 (the maximum limitation of nitrogen) to 1 (without nitrogen limitation). To account, in a very simple manner, for the effects of nitrogen fertilization on plant productivity, we introduced an additive nitrogen response parameter, $N_{\text {add }}$, which is linked to photosynthetic parameters, $V_{\text {cmax_opt }}$ and $J_{\text {max_opt }}$, using 
Table 1. Basic geography and climate information for different crop sites.

\begin{tabular}{lllrrrrrr}
\hline Crop type & SiteID & Country & MAP $^{\mathrm{a}}$ & MAT $^{\mathrm{b}}$ & Longitude & Latitude & Altitude (m) & KGCC $^{\mathrm{c}}$ \\
\hline \multirow{2}{*}{ Winter wheat } & FR-Lam & France & 702 & 12.55 & 1.24 & 43.49 & 180 & Cfb \\
& FR-Gri & France & 579 & 11.5 & 1.95 & 48.84 & 125 & Cfb \\
& FR-Aur & France & 700 & 12.9 & 1.11 & 43.55 & 242.5 & Cfb \\
& DE-Kli & Germany & 674 & 7.1 & 13.52 & 50.89 & 478 & Cfb \\
& Be-Lon & Belgium & 800 & 10 & 4.74 & 50.55 & 165 & Cfb \\
\hline \multirow{2}{*}{ Maize } & FR-Lam & France & 702 & 12.55 & 1.24 & 43.49 & 180 & Cfb \\
& FR-Gri & France & 700 & 11.5 & 1.95 & 48.84 & 125 & Cfb \\
& DE-Kli & Germany & 674 & 7.1 & 13.52 & 50.89 & 478 & Cfb \\
& NL-Lan & Netherland & 786 & 9.8 & 4.9 & 51.95 & -0.7 & Cfb \\
& IT-Bci & Italy & 900 & 15.5 & 14.96 & 40.52 & 20 & Csa \\
\hline
\end{tabular}

Note: ${ }^{a}$ MAP: mean annual precipitation; ${ }^{b}$ MAT: mean annual temperature; ${ }^{c}$ KGCC, the Köppen-Geiger climate classifications.
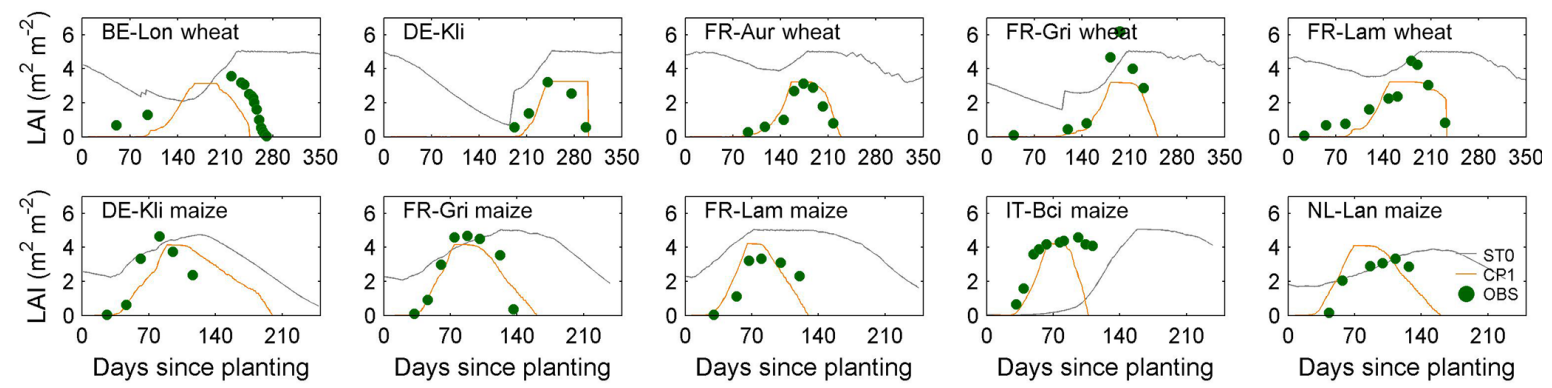

Figure 2. Temporal changes of daily leaf area index (LAI) since planting from observations (green dots), standard ORCHIDEE (ORC-ST0, grey line) and ORCHIDEE-CROP (ORC-CP1, orange line). The upper and lower panel shows the results for different sites of winter wheat and maize, respectively.

the following equation

$N_{\text {add }}=1+N_{\max }-N_{\max } \times 0.75^{\left(N_{\text {fert }} / 30\right)}$,

where $N_{\max }$ is the maximum additive effects of nitrogen fertilization during the growing season, $N_{\text {fert }}$, on the photosynthetic parameters (for details see Chang et al., 2015). The $N_{\text {max }}$ is a PFT-specific parameter that can be calibrated by the observed additive nitrogen fertilization effects on plant productivity (e.g., using field trials). This simple function allowed us to estimate the impacts of different levels of nitrogen fertilization on crop productivity (Chang et al., 2015).

\subsection{Simulation setup}

\subsubsection{Site description}

We tested ORCHIDEE-CROP using winter wheat and maize at seven eddy-covariance sites, which are part of the CarboEurope-IP project (http://www.carboeurope.org/). These sites span different climatic conditions (Table 1 and Fig. S1 in the Supplement). All the sites recorded the meteorological half-hourly variables necessary to run ORCHIDEECROP as well as $\mathrm{CO}_{2}$ fluxes (NEE), and latent and sensible heat fluxes. The NEE half-hourly data were gap filled and partitioned into gross primary productivity (GPP) and total ecosystem respiration (TER) using the online eddy covariance processing tool (Moffat et al., 2007; Papale et al., 2006; Reichstein et al., 2005). Management information (e.g., sowing and harvest date, irrigation and fertilization) and crop development monitoring data (e.g., LAI, aboveground biomass (AGB) and crop yield) were available for each site and were used either for parametriezation (sowing date, fertilization) or evaluation purposes. The geographic locations, climate regimes, and management information are provided in Tables 1, 2, and Fig. S1. More details about the seven sites can be found in Kutsch et al. (2010) and Vitale et al. (2007).

\subsubsection{Climate forcing data and atmospheric $\mathrm{CO}_{2}$}

At each site, meteorological forcing on a half-hour time step was used as a model input. This included air temperature, precipitation, wind speed, atmospheric water vapor pressure, shortwave and longwave incoming radiation, and mean near-surface atmospheric pressure. Annual $\mathrm{CO}_{2}$ atmospheric concentration was derived from background atmospheric measurements. There were gaps in the meteorological data, mainly caused by instrumentation malfunction. Therefore, we reprocessed the data using standardized proce- 
dures for gap-filling and quality control (Moffat et al., 2007; Papale et al., 2006). A significant source of systematic errors in comparisons between modeled and eddy covariance fluxes were attributed to the lack of energy balance closure in the eddy covariance measurements (Foken, 2008). Our evaluation revealed an obvious problem regarding the energy balance closure in the eddy covariance observations on these crop sites where the energy closure rate ranged from $\sim 80.6$ to $86.3 \%$ (e.g., Fig. S2). We thus corrected the daily LE and $\mathrm{H}$ measurements in a similar way to Twine et al. (2000) and Jung et al. (2011), which preserved the Bowen ratio:

$$
\begin{aligned}
E_{\text {corr }} & =\alpha \times E_{\text {uncorr }}=\left(R_{\mathrm{n}}-G\right) /\left(H_{\text {uncorr }}+\mathrm{LE}_{\text {uncorr }}\right) \\
& \times E_{\text {uncorr }},
\end{aligned}
$$

where $E$ is either the LE or $\mathrm{H}$ flux, $\alpha$ is a daily correction factor, and $R_{\mathrm{n}}$ and $G$ are the net radiation and soil heat flux, respectively. In our correction, we do not consider the soil heat flux due to the lack of observations. Although the magnitude and causes of energy budget imbalance probably vary among sites and across timescales (Barr et al., 2006; Franssen et al., 2010), this simplified approach can correct the energy balance closure gap and yields consistent energy fluxes with other independent estimates (Jung et al., 2011).

\subsubsection{Simulation experiments}

A set of simulations were performed for each crop-site (Table 1) using STICS (JavaStics-v11, http://www6.paca. inra.fr/stics/), ORCHIDEE, and ORCHIDEE-CROP to evaluate the performance of ORCHIDEE-CROP and the impacts of the parameterizations of the nitrogen limitation factor and soil hydrology schemes (Table 3). Observed climate data and crop type at each site were used to drive the models (in ORCHIDEE, winter wheat is described by the $\mathrm{C} 3$ crop standard parameters and maize by the standard $\mathrm{C} 4$ crop ones). The same mean soil depth and soil water holding capacity were prescribed for the seven sites, and were averaged from the Harmonized World Soil Database (HWSD; http://webarchive.iiasa.ac.at/ Research/LUC/External-World-soil-database/HTML/). For each site, we selected 1 year of observation during which winter wheat or maize was cultivated. The sowing date was inputted into the model for each crop-site according to the management data (Table 2). However, the harvest date in ORCHIDEE-CROP was determined by crop development processes. The observed nitrogen fertilization and irrigation information for each crop-site were used in STICS experiment STI-WN (Tables 2 and 3). In STICS, the real date and quantity of applied irrigation and nitrogen fertilization can be introduced into the model, which affects the water balance and nitrogen transformation modules, respectively (Brisson et al., 2008).

All simulations based on ORCHIDEE and ORCHIDEECROP started from an equilibrium state of carbon pools where the climate was obtained using a model spin-up. For

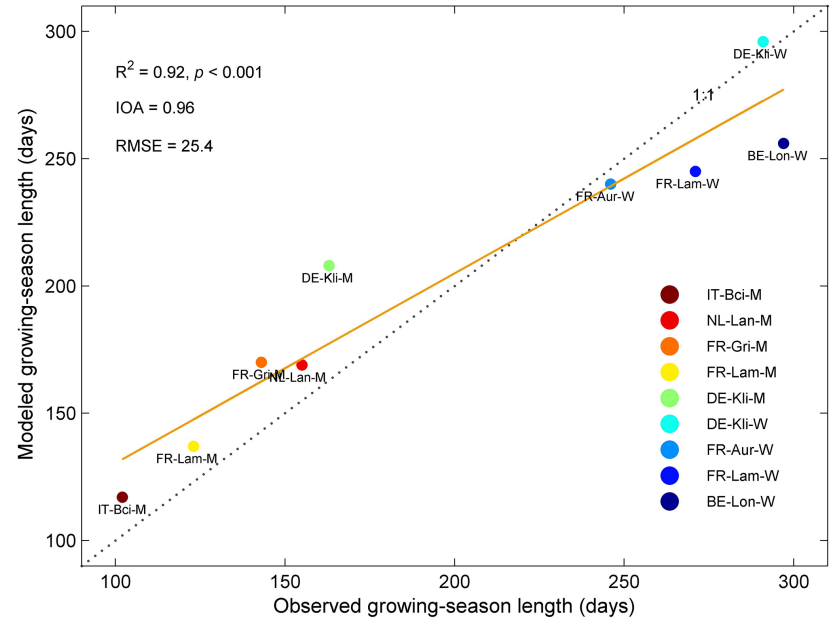

Figure 3. Comparisons of the observed and modeled (ORC-CP1; in detail see Table 3) growing-season lengths (from sowing to maturity) for winter wheat and maize in different sites. Different colors indicate data for different crop-sites.

this spin-up, site-specific meteorological half-hourly data were repeatedly cycled for 300 years to force ORCHIDEE and ORCHIDEE-CROP until the soil water reached a steady state (data not shown). Then, simulations were conducted for the period of evaluation, starting from the initial conditions at the end of model spin-up. Notably, $\mathrm{C}$ input from manure applications was not taken into account in this study due to a lack of data for historical manure applications.

The same cultivar choice (represented by the "Soissons" and "DK250" variety parameters in STICS for winter wheat and maize, respectively), rather than site-year-specific varieties, was made at all sites for winter wheat and maize (see Table 3). This may lead to some discrepancies between simulated and observed values, but our main purpose was to evaluate the improvements achieved by ORCHIDEE-CROP in a generic way, without having to calibrate the model for each site. Sensitivity tests were conducted to evaluate the effects of nitrogen limitation and water stress on crop development, carbon, and energy budgets. The experimental details are shown in Table 3.

\subsection{Metrics for evaluating model performance}

Three metrics were used to evaluate the model-data agreements at a daily resolution for NEE, $\mathrm{H}$, and LE fluxes, and the LAI, AGB, and grain yield biometric variables.

First, we calculated the index of agreement (IOA) (Willmott et al., 1985), given by

$$
\begin{aligned}
\mathrm{IOA}= & 1.0-\sum_{i=1}^{n}\left(O_{i}-P_{i}\right)^{2} / \\
& \sum_{i=1}^{n}\left(\left|P_{i}-\bar{O}\right|+\left|O_{i}-\bar{O}\right|\right)^{2},
\end{aligned}
$$




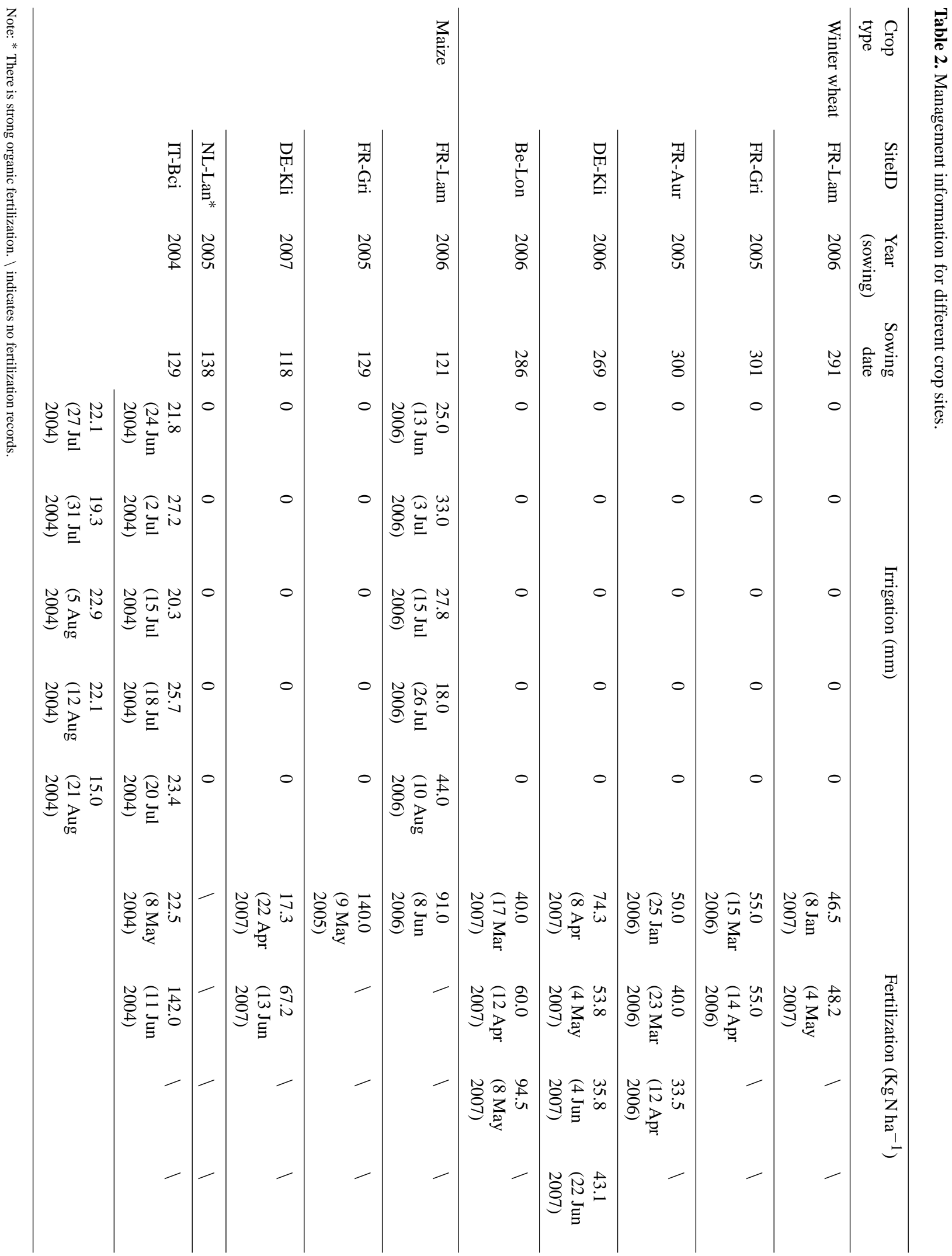




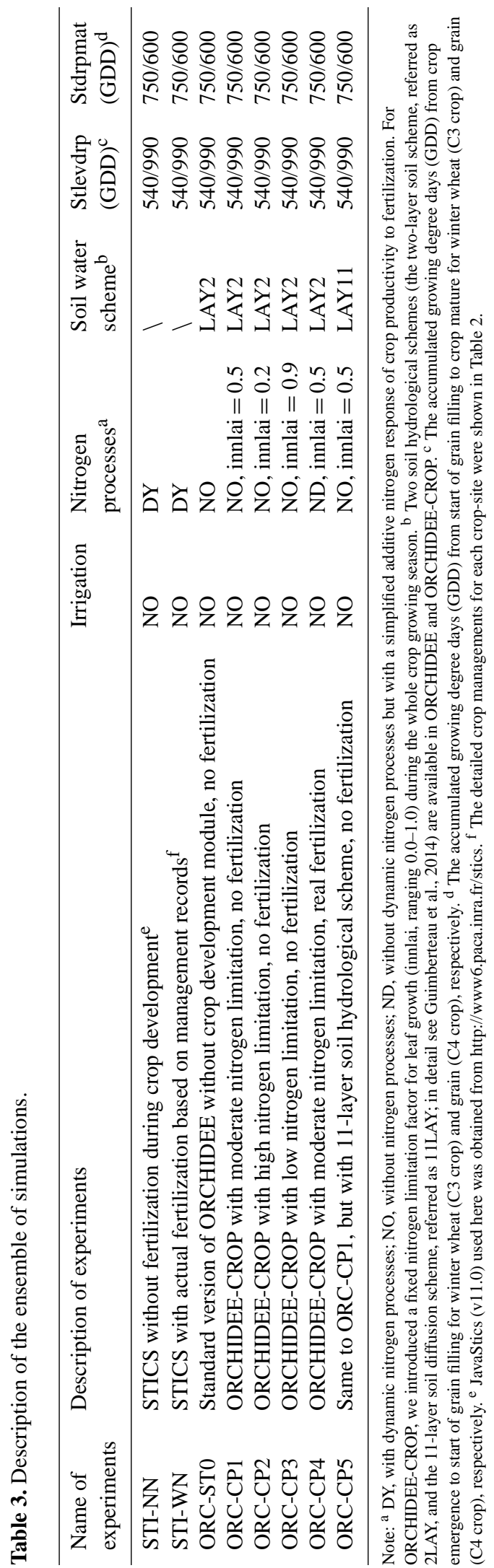

where $P_{i}$ is the modeled data, $O_{i}$ is the observed data, $\bar{O}$ is the observed mean and $n$ is the numbers of data. The IOA, with values ranging from 0.0 to 1.0 , is more sensitive than correlation-based metrics to differences in the observed and modeled means and variances (Willmott et al., 1985).

We also calculated the Pearson's product-moment correlation coefficient for all sites. This metric estimates the proportion of total variance in the observed data that can be explained by model, and is given by

$r=\frac{\sum_{i=1}^{n}\left(P_{i}-\bar{P}\right)\left(O_{i}-\bar{O}\right)}{\sqrt{\sum_{i=1}^{n}\left(P_{i}-\bar{P}\right)^{2}} \sqrt{\sum_{i=1}^{n}\left(O_{i}-\bar{O}\right)^{2}}}$,

where $\bar{P}$ is the modeled mean.

Third, the RMSE and normalized root mean square error (NRMSE) were used to quantify the model-observation agreement in absolute terms, expressed as

$$
\begin{aligned}
& \mathrm{RMSE}=\sqrt{\sum_{i=1}^{n}\left(P_{i}-O_{i}\right)^{2} / n}, \\
& \text { and NRMSE }=\sqrt{\sum_{i=1}^{n}\left(P_{i}-O_{i}\right)^{2} / n /\left(O_{\max }-O_{\min }\right),}
\end{aligned}
$$

where and $O_{\max }$ and $O_{\min }$ are observed maximum and minimum data.

\section{Results}

\subsection{Crop phenology, plant development stages, and productivity}

Comparison of the seasonal evolution of observed and modeled LAI for winter wheat and maize at different sites was shown in Fig. 2. The modeled seasonality for LAI has been markedly improved by ORCHIDEE-CROP (ORC-CP1, Table 3) compared to ORCHIDEE, for both winter wheat and maize. The correlation coefficient between observed daily LAI and modeled daily LAI increased from $0.44 \pm 0.22$ to $0.83 \pm 0.17$ for winter wheat and from $0.64 \pm 0.22$ to $0.79 \pm 0.10$ for maize from ORCHIDEE to ORCHIDEE-CROP (ORC-CP1), respectively. The IOA increased from $0.47 \pm 0.11$ to $0.82 \pm 0.12$ (winter wheat) and from $0.57 \pm 0.15$ to $0.85 \pm 0.08$ (maize), with a significant decrease in RMSE $(2.71 \pm 0.49$ vs. $1.12 \pm 0.36$ and $2.06 \pm 0.86$ vs. $1.04 \pm 0.31$ for winter wheat and maize, respectively) (Figs. 2, 5a-b, Table 4). Despite its overall good performance for LAI, ORC-CP1 (under moderate nitrogen limitation of leaf growth) could not reproduce the observed LAI within the measurement uncertainty (personal communications with PIs in 2014) at a few sites (Fig. 2). For example, maximum LAI was underestimated by 49 and $28 \%$ for winter wheat at FR-Gri and FR-Lam, respectively. Reducing the nitrogen limitation of leaf growth (ORC-CP3) at these two sites could improve the modeled maximum LAI 


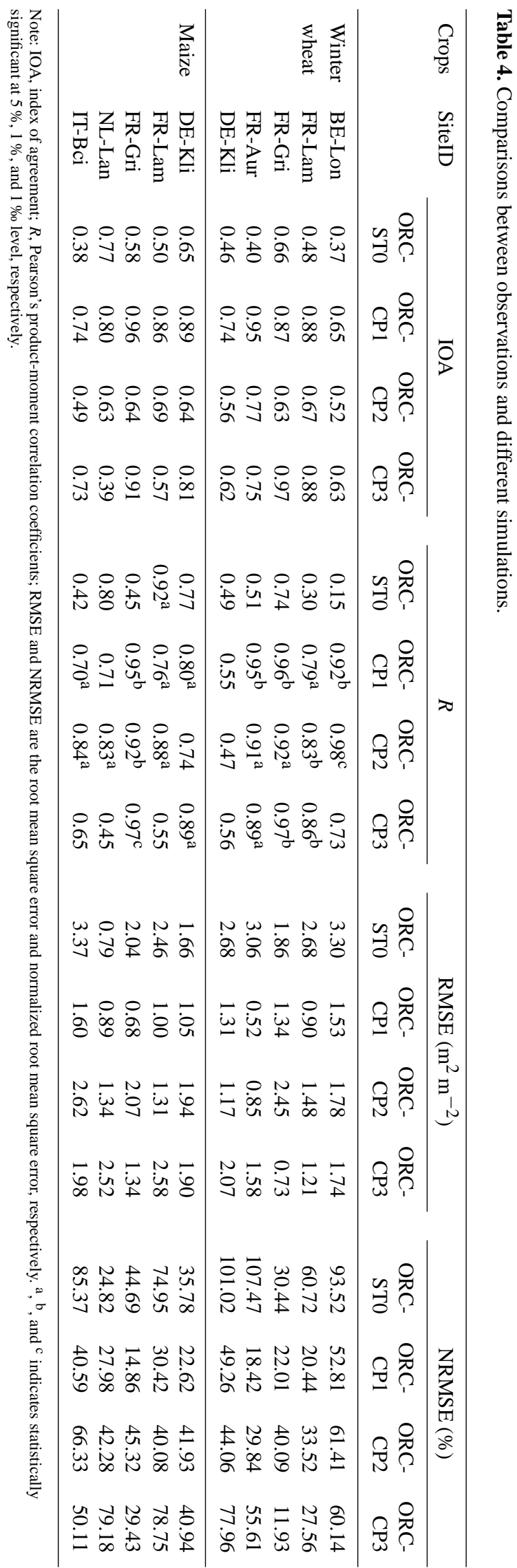

and bring it into agreement with the observations (Fig. S3, Table 4). The modeled growing-season length (defined as the period from crop sowing to harvest) by ORC-CP1 for all crop sites was in good agreement with the observations $(\mathrm{IOA}=0.96$ and $\mathrm{RMSE}=25.4$ days $)$ (Fig. 3 ).

The accurately simulated timing and amplitude of LAI improved the seasonal evolution of aboveground biomass (AGB) in ORCHIDEE-CROP (ORC-CP1) compared to ORCHIDEE for both winter wheat and maize, except at BE-Lon for winter wheat and at NL-Lan for maize (Figs. 4, 5). In general, the bias of the modeled AGB was attributable to the bias in the modeled LAI as indicated by the significant $(p<0.005)$ relationship between AGB and LAI for all sites (Fig. S4). However, the daily change rate of aboveground biomass in the late growing season between the start of grain filling and yield harvest was systematically and significantly $(p<0.05)$ underestimated for both winter wheat (change rate of AGB underestimated by 36-74\%) and maize (18-70\%), especially at the sites where LAI was underestimated (e.g., winter wheat at FR-Gri and FR-Lam) (Figs. 2, 4, S5). The observation data did not show a decrease in aboveground biomass until harvest (Fig. 4).

ORCHIDEE-CROP (ORC-CP1) could capture the timing of grain filling and yield harvest well compared to the observations and STICS simulations (Fig. S6). Comparisons of modeled and observed crop yields for winter wheat and maize in FR-Aur and FR-Lam showed that there was a 19 to $30 \%$ underestimation of crop yields in ORC-CP1 without fertilization (Fig. 6), compared to a good match (NRMSE $=\sim 8.8 \%$ ) between STICS with real fertilization (STI-WN) and the observed data (Fig. S6). However ORCHIDEE-CROP with real fertilization (ORC-CP4) could produce a better estimation of crop yields for these two sites than ORCHIDEE-CROP without fertilization (ORC-CP1), leading to a $50 \%$ reduction in the NRMSE (47 vs. $23 \%$ for ORC-CP1 vs. ORC-CP4, respectively) (Fig. 6). Considering the measurement uncertainties of FR-Aur and FRLam for crop yields (personal communications with PIs in 2014), ORCHIDEE-CROP, with its simple nitrogen fertilization parameterization, generally showed reasonable performance compared to STICS, which has a complete nitrogen cycle and captures both the timing and amplitude of crop yields.

\section{2 $\mathrm{CO}_{2}$ and energy fluxes}

ORCHIDEE-CROP had a more realistic simulated seasonality and amplitude for NEE at most of the winter wheat sites than ORCHIDEE (significant increase in IOA and $r$ and decrease in RMSE from $2.9 \pm 0.2 \mathrm{~g} \mathrm{C} \mathrm{m}^{-2} \mathrm{day}^{-1}$ in ORCHIDEE to $1.9 \pm 0.5 \mathrm{~g} \mathrm{C} \mathrm{m}^{-2} \mathrm{day}^{-1}$ in ORC-CP1). Improved performances of ORCHIDEE-CROP over ORCHIDEE were also found at the maize sites in humid regions (Figs. S1, 7). Along with leaf area development during the growing season, the model produced a $\mathrm{CO}_{2}$ sink until shortly 

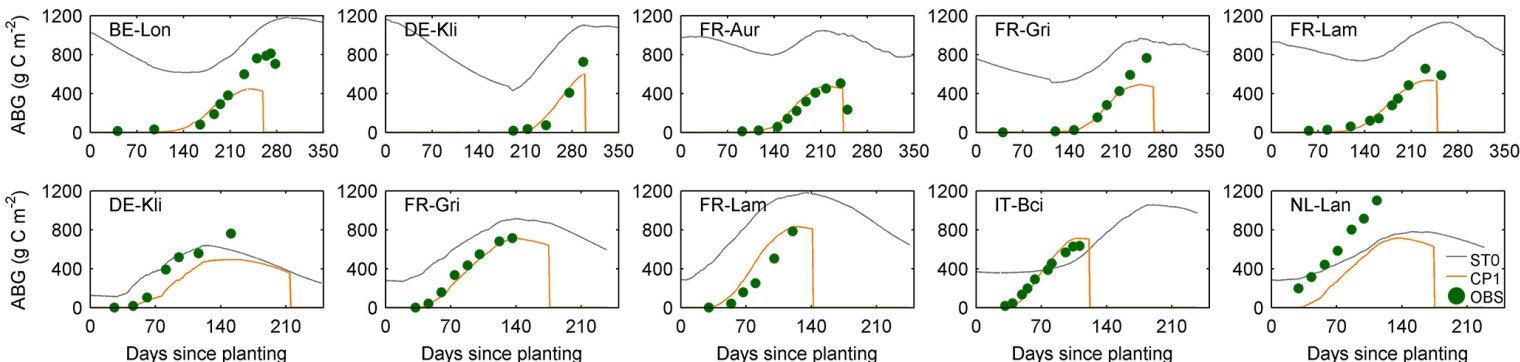

Figure 4. Comparisons of the observed (green dots) and modeled daily aboveground biomass from ORCHIDEE-CROP (ORC-CP1, orange line) and ORCHIDEE (ORC-ST0, grey line) for winter wheat and maize in different sites. The upper and lower panel shows the results for different sites of winter wheat and maize, respectively.
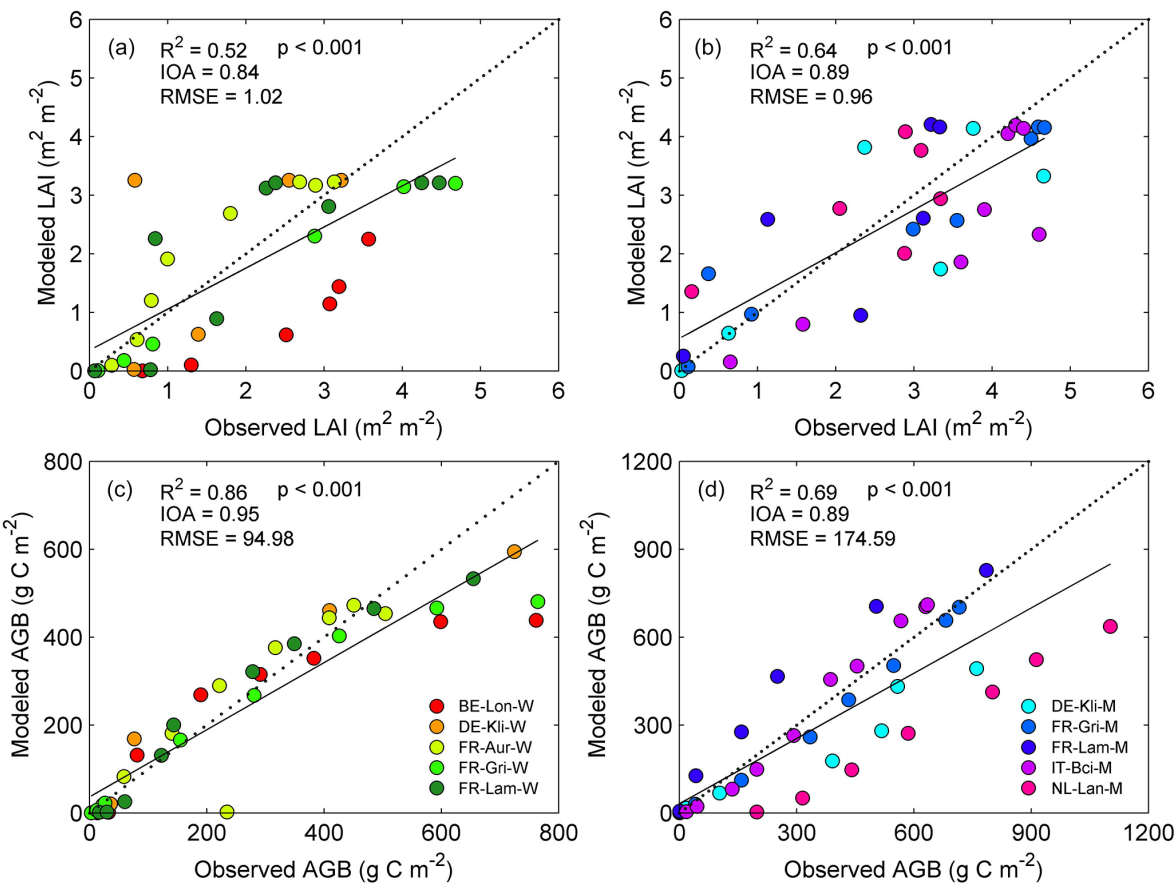

Figure 5. Scatter plots of the modeled (ORC-CP1; in detail see Table 3) and observed daily LAI and aboveground biomass (AGB) for different sites of winter wheat (a and c) and maize (b and d), respectively. The units for RMSE of LAI and AGB are $\mathrm{m}^{2} \mathrm{~m}^{-2} \mathrm{and} \mathrm{g} \mathrm{C}^{-2}$, respectively. Different colors indicate different crop-sites with red, orange, light green, green, and dark green for winter wheat (-W) at BE-Lon, DE-Kli, FR-Aur, FR-Gri, and FR-Lam, respectively, and with light blue, medium blue, blue, purple, and violet for maize (-M) at DE-Kli, FR-Gri, FR-Lam, IT-Bci, and NL-Lan, respectively.

before harvest, when most leaves were senescent and crop photosynthesis could not compensate for respiration, which was consistent with the observed data (Fig. 7). ORCHIDEECROP could also capture the observed peak in $\mathrm{CO}_{2}$ release to atmosphere shortly (ranging from 10 to 20 days, Fig. 7) after harvest for both winter wheat and maize, which was mainly due to increased litter decomposition.

However, there was a mismatch between the simulations and observations regarding the temporal evolution of NEE for winter wheat in BE-Lon, where there was a weaker and earlier termination of $\mathrm{CO}_{2}$ uptake in the model (Fig. 7). The underestimated LAI and earlier cessation of crop growth in
ORC-CP1 at this site resulted in a negative bias for GPP during the late growing season ( $\sim 170$ days after sowing $)$ (Figs. 2, S7), which contributed to the underestimation of NEE uptake (Figs. 7, S8). Notably, ORC-CP1 overestimated the NEE peak uptake of $\mathrm{CO}_{2}$ for maize at sites with drier climates in Europe (e.g., FR-Lam and IT-Bci). The overestimation of NEE at these summer-dry sites was probably $(68-85 \%$ of explained variance revealed by the general linear model) caused by an overestimation of GPP rather than by an underestimation of ecosystem respiration in ORC-CP1 (Figs. S7, S8). Further analysis showed a much higher $(p<0.05)$ rate for GPP per unit LAI in ORC-CP1 


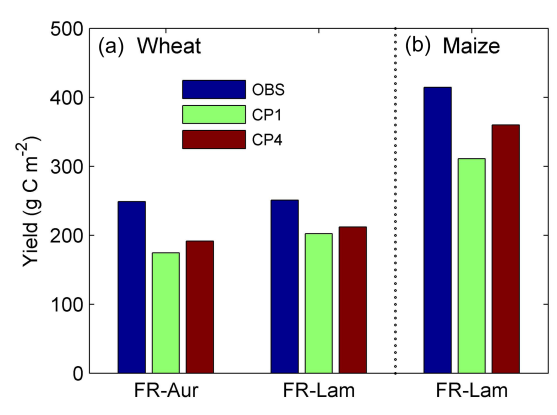

Figure 6. Comparisons of the observed (blue bars) and modeled (green bars for ORC-CP1 and brown bars for ORC-CP4; see Table 3) harvested crop yields in different sites for winter wheat (a) and maize (b).

than observed at the southern maize sites (Fig. S9). Notably, ORCHIDEE-CROP with the 11-LAY hydrological scheme (ORC-CP5) improved the modeled NEE for maize at these sites because it showed a $40 \%$ decrease in the NRMSE (Fig. 7).

Despite the improved seasonality of $\mathrm{H}$ for most of the crop-sites over Europe (Fig. S10), ORCHIDEE-CROP with the 2LAY hydrological scheme generally overestimated $\mathrm{H}$ for winter wheat sites, especially in the early- and midgrowing season (from sowing to 160-200 days after sowing) and showed a more realistic simulation of $\mathrm{H}$ for maize sites (NRMSE of 9-13\%). The overestimation of $\mathrm{H}$ at wheat sites occurred during the early- and mid-growing season (Fig. 8) when the plants were growing slowly with a low canopy cover. This could be partly attributed to the underestimation of soil water content in the top soil during that period (data not shown) or to the insufficiently deep roots prescribed in the model. Notably, the ORC-CP5 with the 11LAY soil hydrological scheme, which had a more realistic representation of soil water infiltration after rain and could simulate the vertical profile of soil moisture with desiccation of the surface soil during dry episodes, improved the simulation of $\mathrm{H}$ during this period, with the NRMSE being brought down from $7-10 \%$ in ORC-CP1 to $5-8 \%$ in ORC-CP5 (Fig. 8). Notably, however, the 11LAY hydrological scheme usually overestimated the bare soil evaporation (data not shown), which would result in drier top soil conditions and lead to a higher $\mathrm{H}$. This could partially explain the residual overestimation of $\mathrm{H}$, even in ORC-CP5 (Fig. S10).

Consistent with the overestimation of $\mathrm{H}$ in ORC-CP1, LE was generally underestimated at the wheat sites (Fig. 9). A more realistic estimation of LE was obtained by ORCCP5 for a majority of the sites, showing a $32 \%$ decrease in NRMSE from ORC-CP1 to ORC-CP5. The exceptions were the winter wheat and maize simulation at the DE-Kli site, which could be attributed to a considerable energy balance gap (with an energy closure of $\sim 73 \%$ ) at this site (Fig. 9). For maize, ORC-CP5 overestimated LE at DE-Kli by $\sim 110 \%$ compared to the observed data. The LE values were also overestimated for wheat during the early- and midgrowing season (from sowing to 230 days after sowing). The overestimation of LE at DE-Kli was not explained by the LAI bias (see above) nor by a systematic error in LE due to the effects of rainfall events (with daily rainfall $\geq 3 \mathrm{~mm}$ ) (Figs. 89), but was possibly due to some other factors, such as soil water holding capacity. The slightly negative bias in LE simulated by ORC-CP5 at the wheat site FR-Lam during the peak leaf growth (210-250 days after planting) was due to an underestimation of the LAI (Figs. 9, 2). The slight overestimation of LAI for maize during periods of peak leaf growth (e.g., FR-Lam and NL-Lan) did not translate into a related overestimation of LE. This illustrated the divergent responses of LE to changes in LAI between ORCHIDEE-CROP and the observations, which could be due to several factors, such as the parameterization of soil water stress (Fig. S11). The episodes of LE with low biases (during LE peaks) coincided with high $\mathrm{H}$ biases, even though net radiation appeared to be realistic, except for the maize site IT-Bci in Italy (Fig. S12).

ORCHIDEE-CROP could also capture the spatial gradients of carbon and energy fluxes across different crop sites in Europe. There were significant correlation coefficients between the observed and modeled GPP, NEE, H, and LE data, with $r$ ranging from 0.75 to 0.90 . Evaluation of IOA revealed a generally good agreement between the observed and modeled GPP, NEE, H, and LE data with IOA ranging from 0.70 to 0.90 (Figs. 10, S14-S16).

\section{Discussion}

\subsection{General performance of ORCHIDEE-CROP}

ORCHIDEE-CROP has been developed as an Agro-LSM and adopts a generic framework to integrate the crop processes from STICS into the ORCHIDEE LSM. Given its generic structure, ORCHIDEE-CROP, tested using wheat and maize in this study, can simulate other crop types. Crop phenology, development, carbon allocation, and grain filling can be calculated from climate forcing data and is mediated by limiting factors (e.g., nitrogen, extreme temperatures, and low soil moisture).

A significant improvement was obtained using ORCHIDEE-CROP compared to ORCHIDEE for the simulated crop phenology and development at different winter wheat and maize sites. It showed $65-95 \%$ (IOA) for biometric data and 78-98\% (IOA) agreement with the observed data for all turbulent fluxes, despite the lack of detailed crop management (e.g., irrigation, fertilization) parameterization (Figs. 2-9) and the lack of an explicit calculation for the nitrogen cycle in the croplands.

Remarkably, ORCHIDEE-CROP has a good ability to reproduce the observed spatial gradients for carbon and energy fluxes across different climate zones in Europe, even using a fixed variety parameter setting for different sites. This im- 

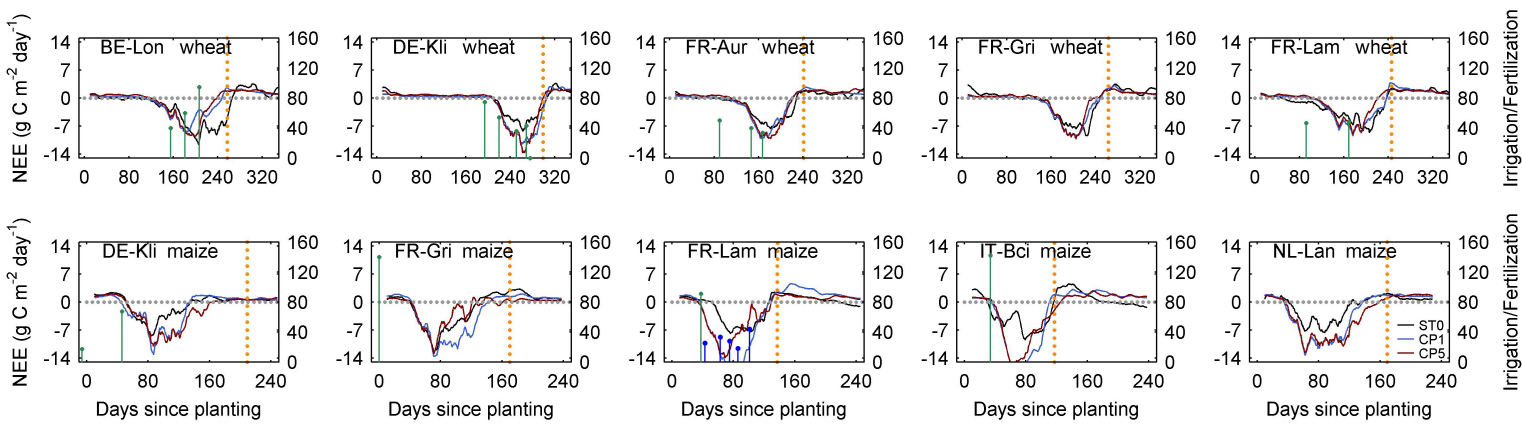

Figure 7. Temporal changes of daily net ecosystem exchanges (NEE) derived from observations (black line) and ORCHIDEE-CROP (ORCCP1, blue line; ORC-CP5, brown line) since planting. The green and blue stems represent the fertilization $\left(\mathrm{kg} \mathrm{N}^{-1}\right)$ and irrigation (mm) events during the selected growing season. The dotted orange line indicates the harvest date since planting. The upper and lower panel shows the results for different sites of winter wheat and maize, respectively.
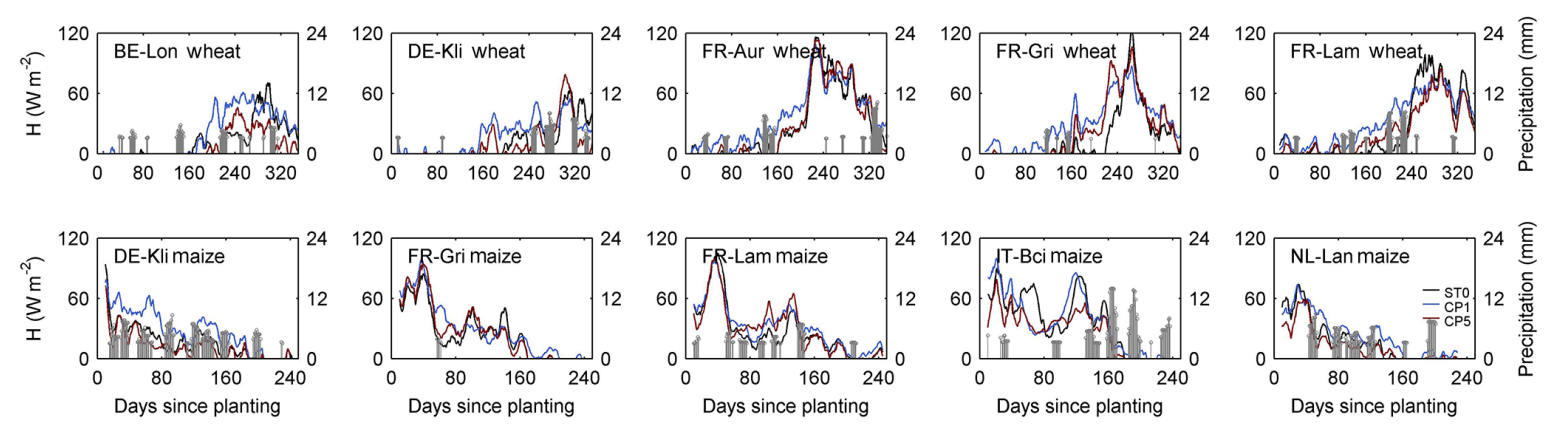

Figure 8. Comparisons between the observed (black line) and modeled daily sensible heat fluxes (H) from ORCHIDEE-CROP (ORC-CP1, blue line; ORC-CP5, brown line) for different crop-sites. The grey stems represent the relative large rainfall events (with daily summed rainfall $\geq 3 \mathrm{~mm}$ ) during the modeled growing season. The upper and lower panel shows the results for different sites of winter wheat and maize, respectively.

plied that these spatial gradients in biophysical and biochemical variables are mainly driven by climate rather than by crop variety.

Improvements in crop phenology and carbon allocation led to a general good match of the seasonality between modeled and observed AGB (with NRMSEs of 11-54\%), crop yields, and carbon and energy fluxes (NRMSEs of 9.0-20.1 and $9.4-22.3 \%$ for NEE and sensible and latent heat fluxes, respectively). Comparisons between the $2 \mathrm{LAY}$ and 11LAY hydrological schemes revealed that the 11LAY hydrological scheme can improve the modeling of soil water dynamics and hence lead to a better simulation of leaf growth and consequent biochemical and biophysical variables, especially for the $\mathrm{C} 4$ crops planted in the drier climate zones of Europe (Figs. 7-9). This in turn exerts great effects on the estimations of carbon balances in these regions, especially in the context of the projected increasing climate variability and extremes (e.g., heat waves and drought events) (Beniston et al., 2007; Ciais et al., 2005; Stocker et al., 2013). Yet, parameterization of water stress also depends on the distribution of active roots, which is considered as fixed in all ORCHIDEE versions. The use of a static root profile is one limit on the calculation of water stress, but the use of 11-layer hydrology allows us to simulate shifts in root uptake from the surface to deeper horizons as the soil dries out during drought. An important area for further research could be a more mechanistic parameterization of the root profile in the model.

Notably, the simple function of additive nitrogen fertilization on crop productivity can lead to better agreement between the observed and modeled crop yields in ORCHIDEE-CROP, which showed a $50 \%$ decrease in the NRMSE (Fig. 6). The remaining discrepancies in simulated crop yields and energy fluxes are generally within the observed uncertainties for measurement and energy balance closure. More importantly, ORCHIDEE-CROP has the ability to capture the spatial gradients of crop-related flux variables, such as GPP, NEE, H, and LE, across the studied sites in the different European climate zones (Figs. 10, S14-S16). This is important for further applications of this model using gridded data over Europe, or even the globe, when attempting to investigate regional/global yield variations and the interactions between croplands and the climate system. Croplands have potentially crucial climate feedbacks regarding the increased intensification of agricultural activities and land use 

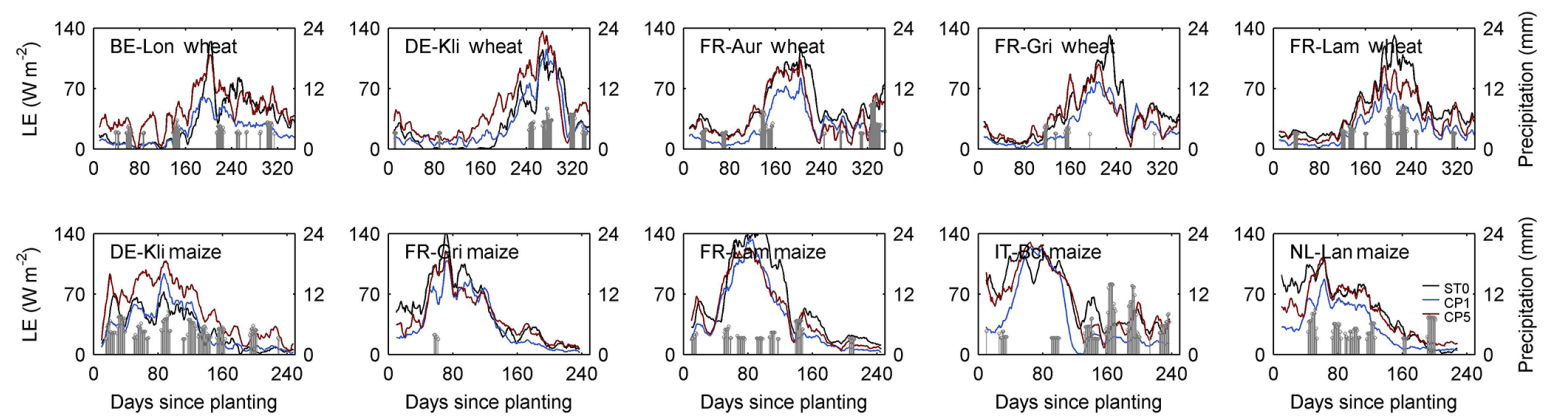

Figure 9. Same to Fig. 8 except for latent heat fluxes (LE).

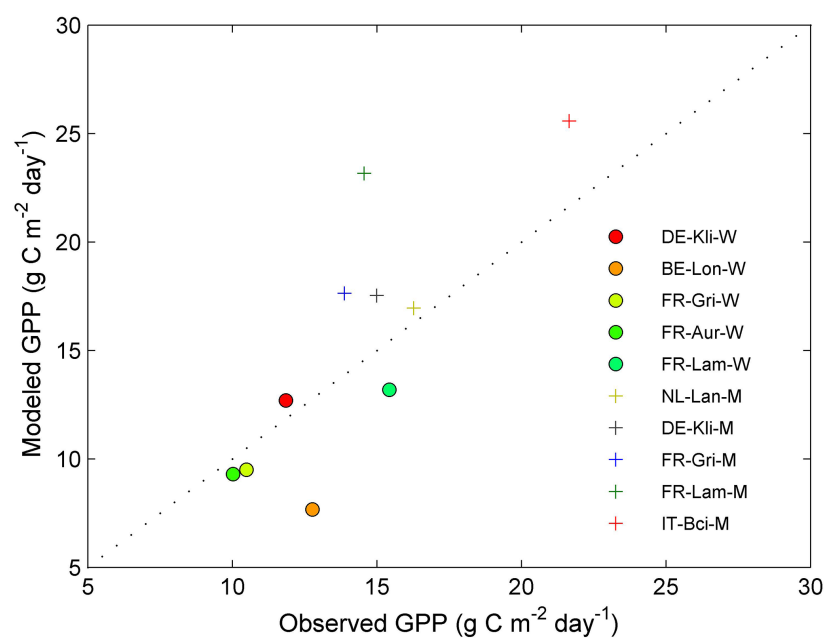

Figure 10. Comparisons between the observed and modeled (based on ORC-CP5) mean growing-season GPP among different crop sites for winter wheat (circle, -W) and maize (cross, -M). Different colors indicate different sites.

changes (Pitman et al., 2009; Ramankutty et al., 2002; Sacks and Kucharik, 2011).

Failure of the model to capture the peak LAI at some crop sites (e.g., winter wheat at FR-Gri and FR-Lam) under ORC$\mathrm{CP} 1$ is partly attributed to the simplified representation of nitrogen limitation on crop growth and fertilization effects (Sect. 2). Alleviation of nitrogen limitation on leaf growth at those sites can improve the simulated amplitudes of LAI and capture the maximum LAI (Fig. S3). Nitrogen limitation has a strong influence on the seasonal evolution of crop growth (Fig. S3). A more realistic representation of intra-seasonal nitrogen processes (results based on STICS with an explicit nitrogen cycle) leads to a generally much better match between the modeled and observed LAI, except for NL-Lan and maize (Fig. S13).

The failure to model irrigation effects can also introduce some bias to the simulated LAI and other variables. Soil water stress on GPP and LE, which also affects carbon allocation, plays an important role in controlling crop development, especially for summer crops (e.g., maize) planted in regions with dry summer episodes (Fig. S1, Table 1). Those regions are currently suffering from intensive irrigation management (Table 2) and there will possibly be an increase in irrigation requirements as the climate warms (Döll, 2002). As illustrated by our results the lack of irrigation management in the current version of ORCHIEE-CROP leads to a lower LAIs in the later crop season at FR-Lam for maize in drier climate zones (Figs. 2 and 7), which, in turn, affect NEE and the energy budget (Figs. 7-9). More importantly, the projected increased drought stress for cultivated croplands (Dai, 2012), with a more intense and longer lasting droughts in drier climate zones (Davin et al., 2014; Trenberth et al., 2014), challenges the representations of soil hydro-logical processes and their interactions with other factors for existing Agro-LSMs.

\subsection{Model limitation and uncertainty}

Irrigation (as discussed above) effects on the crop development and yields are not accounted for in the current version of ORCHIDEE-CROP, but it is important when attempting to investigate the historically long-term changes in crop yields over recent decades, as intensive human management has tended to occur since approximately the middle of the 20th century.

Several studies have shown that the spatial differences in crop management contribute significantly to the tempospatial patterns of crop yields (Licker et al., 2010; Lobell and Field, 2007), as well as the impacts of climate and soil fertility (Rosenzweig et al., 2014). Adaptive improvements in agricultural management are regarded as a potential way to close the yield gaps in a relatively sustainable manner (Licker et al., 2010). How the model handles human management factors (e.g., irrigation and fertilization) and their interactions with changing $\mathrm{CO}_{2}$ and climate variations could have significant impacts on the crop production simulations and the consequent land surface carbon budgets (Prescher et al., 2010). Additionally, our current crop development module embodies a number of simplifications for pests, diseases, and weeds, which we assumed to be controlled. Extreme soil conditions (e.g., high salinity or acidity) are also crudely assumed to 
have little effect on crop growth. These factors can also introduce great uncertainties into the biophysical and biochemical simulations of croplands.

Therefore, explicit nutrition dynamics and a human management (irrigation, fertilization, introduction of new crop varieties, and pest management, etc.) module need to be included in the updated version of ORCHIDEE-CROP to improve our ability to understand and project the roles of croplands in food security, environmental footprints, and ecosystem services in response to climate change.

\section{Conclusions}

ORCHIDEE-CROP, by integrating a generic process-based crop development and yield harvest module into a generic LSM-ORCHIDEE program, allow us to assess the spatial and temporal dynamics of the important biophysical and biochemical interactions within the soil-vegetationatmosphere continuum for temperate crops. Comprehensive evaluations show the generally good performance of ORCHIDEE-CROP at predicting crop phenology, productivity, and the biosphere-atmosphere carbon and energy exchanges in pan-Europe temperate crop sites covering different climate zones, even without the explicit human management module. It benefits from a generic strategy in the crop module, which makes ORCHIDEE-CROP widely applicable at the regional and global scale. Explicit parameterizations of crop development processes in ORCHIDEE-CROP can improve the simulations of both the seasonality and magnitudes of LAI for croplands, which in turn affect the consequent surface roughness, surface albedo, water, energy, and carbon budgets for land surfaces. Therefore, with respect to future climate change, ORCHIDEE-CROP will allow us to predict the footprints of climate variations on food security, and to simultaneously account for feedbacks caused by changes in crop behaviors to the atmosphere by coupling it to a general atmospheric circulation model (e.g., LMDz).

Nevertheless, further improvement, especially with regards to explicit nutritional dynamics and human management, is a primary priority and could significantly improve our ability to understand and predict the role of croplands in the biosphere-atmosphere continuum, in the context of the increasing global demand for food and the urgent requirement to reduce the environmental footprints (Godfray et al., 2010; Mueller et al., 2012).

\section{Code availability}

The ORCHIDEE-CROP is still undergoing development, especially for human management processes, and the code is modified frequently. Therefore, the codes are not ready for full public access. However, the source codes of ORCHIDEE-CROP at an early version (V0) can be re- quested from Xiuchen Wu (xiuchen.wu@bnu.edu.cn) or Nicolas Vuichard (nicolas.vuichard@1sce.ipsl.fr).

\section{The Supplement related to this article is available online at doi:10.5194/gmd-9-857-2016-supplement.}

Acknowledgements. We thank Jinfeng Chang, and Chao Yue from Laboratoire des Sciences du Climat et de l'Environnement (LSCE) of France for their valuable help for Fortran coding. This work was supported by the EU FP7 project GHG-Europe (Greenhouse gas management in European land use systems; grant no. 244122).

Edited by: A. B. Guenther

\section{References}

Asseng, S., Ewert, F., Rosenzweig, C., Jones, J., Hatfield, J., Ruane, A., Boote, K., Thorburn, P., Rötter, R., and Cammarano, D.: Uncertainty in simulating wheat yields under climate change, Nature Climate Change, 3, 827-832, 2013.

Barr, A., Morgenstern, K., Black, T., McCaughey, J., and Nesic, Z.: Surface energy balance closure by the eddy-covariance method above three boreal forest stands and implications for the measurement of the $\mathrm{CO}_{2}$ flux, Agr. Forest Meteorol., 140, 322-337, 2006.

Bassu, S., Brisson, N., Durand, J.-L., Boote, K., Lizaso, J., Jones, J. W., Rosenzweig, C., Ruane, A. C., Adam, M., Baron, C., Basso, B., Biernath, C., Boogaard, H., Conijn, S., Corbeels, M., Deryng, D., De Sanctis, G., Gayler, S., Grassini, P., Hatfield, J., Hoek, S., Izaurralde, C., Jongschaap, R., Kemanian, A. R., Kersebaum, K. C., Kim, S.-H., Kumar, N. S., Makowski, D., Müller, C., Nendel, C., Priesack, E., Pravia, M. V., Sau, F., Shcherbak, I., Tao, F., Teixeira, E., Timlin, D., and Waha, K.: How do various maize crop models vary in their responses to climate change factors?, Glob. Change Biol., 20, 2301-2320, 2014.

Beniston, M., Stephenson, D. B., Christensen, O. B., Ferro, C. A., Frei, C., Goyette, S., Halsnaes, K., Holt, T., Jylhä, K., and Koffi, B.: Future extreme events in European climate: an exploration of regional climate model projections, Climatic Change, 81, 71-95, 2007.

Berg, A., Sultan, B., and de Noblet-Ducoudré, N.: Including tropical croplands in a terrestrial biosphere model: application to West Africa, Climatic Change, 104, 755-782, 2011.

Bonan, G. B.: Observational evidence for reduction of daily maximum temperature by croplands in the Midwest United States, J. Climate, 14, 2430-2442, 2001.

Bonan, G. B.: Forests and climate change: forcings, feedbacks, and the climate benefits of forests, Science, 320, 1444-1449, 2008

Bondeau, A., Smith, P. C., Zaehle, S., Schaphoff, S., Lucht, W., Cramer, W., Gerten, D., Lotze-Campen, H., Müller, C., and Reichstein, M.: Modelling the role of agriculture for the 20th century global terrestrial carbon balance, Glob. Change Biol., 13, 679-706, 2007. 
Brisson, N., Mary, B., Ripoche, D., Jeuffroy, M. H., Ruget, F., Nicoullaud, B., Gate, P., Devienne-Barret, F., Antonioletti, R., and Durr, C.: STICS: a generic model for the simulation of crops and their water and nitrogen balances. I. Theory and parameterization applied to wheat and corn, Agronomie, 18, 311-346, 1998.

Brisson, N., Ruget, F., Gate, P., Lorgeou, J., Nicoullaud, B., Tayot, X., Plenet, D., Jeuffroy, M.-H., Bouthier, A., and Ripoche, D.: STICS: a generic model for simulating crops and their water and nitrogen balances. II. Model validation for wheat and maize, Agronomie, 22, 69-92, 2002.

Brisson, N., Launay, M., Mary, B., and Beaudoin, N.: Conceptual basis, formalisations and parameterization of the STICS crop model, Edition Quae, Versailles CEDEX, 2008.

Chang, J., Viovy, N., Vuichard, N., Ciais, P., Campioli, M., Klumpp, K., Martin, R., Leip, A., and Soussana, J.: Modelled changes in potential grassland productivity and in ruminant livestock density in Europe over 1961-2010, PLoS One, 10, e0127554, doi:10.1371/journal.pone.0127554, 2015.

Ciais, P., Reichstein, M., Viovy, N., Granier, A., Ogée, J., Allard, V., Aubinet, M., Buchmann, N., Bernhofer, C., and Carrara, A.: Europe-wide reduction in primary productivity caused by the heat and drought in 2003, Nature, 437, 529-533, 2005.

Ciais, P., Gervois, S., Vuichard, N., Piao, S., and Viovy, N.: Effects of land use change and management on the European cropland carbon balance, Glob. Change Biol., 17, 320-338, 2011.

Collatz, G. J., Ribas-Carbo, M., and Berry, J.: Coupled photosynthesis-stomatal conductance model for leaves of $\mathrm{C} 4$ plants, Funct. Plant Biol., 19, 519-538, 1992.

Dai, A.: Increasing drought under global warming in observations and models, Nature Climate Change, 3, 52-58, 2012.

Davin, E. L., Seneviratne, S. I., Ciais, P., Olioso, A., and Wang, T.: Preferential cooling of hot extremes from cropland albedo management, P. Natl. Acad. Sci. USA, 111, 9757-9761, 2014.

de Noblet-Ducoudré, N., Gervois, S., Ciais, P., Viovy, N., Brisson, N., Seguin, B., and Perrier, A.: Coupling the soil-vegetationatmosphere-transfer scheme ORCHIDEE to the agronomy model STICS to study the influence of croplands on the European carbon and water budgets, Agronomie, 24, 397-407, 2004.

Döll, P.: Impact of climate change and variability on irrigation requirements: a global perspective, Climatic Change, 54, 269-293, 2002.

Farquhar, G., von Caemmerer, S. v., and Berry, J.: A biochemical model of photosynthetic $\mathrm{CO}_{2}$ assimilation in leaves of $\mathrm{C} 3$ species, Planta, 149, 78-90, 1980.

Foken, T.: The energy balance closure problem: An overview, Ecol. Appl., 18, 1351-1367, 2008.

Foley, J. A., Ramankutty, N., Brauman, K. A., Cassidy, E. S., Gerber, J. S., Johnston, M., Mueller, N. D., O'Connell, C., Ray, D. K., and West, P. C.: Solutions for a cultivated planet, Nature, 478, 337-342, 2011.

Franssen, H., Stöckli, R., Lehner, I., Rotenberg, E., and Seneviratne, S.: Energy balance closure of eddy-covariance data: A multisite analysis for European FLUXNET stations, Agr. Forest Meteorol., 150, 1553-1567, 2010.

Friedlingstein, P., Joel, G., Field, C., and Fung, I.: Toward an allocation scheme for global terrestrial carbon models, Glob. Change Biol., 5, 755-770, 1999.
Georgescu, M., Lobell, D., and Field, C.: Potential impact of US biofuels on regional climate, Geophys. Res. Lett., 36, L21806, doi:10.1029/2009GL040477, 2009.

Gervois, S., de Noblet-Ducoudré, N., Viovy, N., Ciais, P., Brisson, N., Seguin, B., and Perrier, A.: Including croplands in a global biosphere model: methodology and evaluation at specific sites, Earth Interact., 8, 1-25, 2004.

Gervois, S., Ciais, P., de Noblet-Ducoudré, N., Brisson, N., Vuichard, N., and Viovy, N.: Carbon and water balance of European croplands throughout the 20th century, Global Biogeochem. Cy., 22, GB2022, doi:10.1029/2007GB003018, 2008.

Godfray, H. C. J., Beddington, J. R., Crute, I. R., Haddad, L., Lawrence, D., Muir, J. F., Pretty, J., Robinson, S., Thomas, S. M., and Toulmin, C.: Food security: the challenge of feeding 9 billion people, Science, 327, 812-818, 2010.

Guimberteau, M., Ducharne, A., Ciais, P., Boisier, J. P., Peng, S., De Weirdt, M., and Verbeeck, H.: Testing conceptual and physically based soil hydrology schemes against observations for the Amazon Basin, Geosci. Model Dev., 7, 1115-1136, doi:10.5194/gmd7-1115-2014, 2014.

IPCC: Climate Change 2014: Impacts, Adaptation, and Vulnerability, Cambridge, United Kingdom and New York, NY, USA, 2014.

Jung, M., Reichstein, M., Margolis, H. A., Cescatti, A., Richardson, A. D., Arain, M. A., Arneth, A., Bernhofer, C., Bonal, D., Chen, J., Gianelle, D., Gobron, N., Kiely, G., Kutsch, W., Lasslop, G., Law, B. E., Lindroth, A., Merbold, L., Montagnani, L., Moors, E. J., Papale, D., Sottocornola, M., Vaccari, F., and Williams, C.: Global patterns of land-atmosphere fluxes of carbon dioxide, latent heat, and sensible heat derived from eddy covariance, satellite, and meteorological observations, J. Geophys. Res.-Biogeo., 116, G00J07, doi:10.1029/2010JG001566, 2011.

Krinner, G., Viovy, N., de Noblet-Ducoudré, N., Ogée, J., Polcher, J., Friedlingstein, P., Ciais, P., Sitch, S., and Prentice, I. C.: A dynamic global vegetation model for studies of the coupled atmosphere-biosphere system, Global Biogeochem. Сy., 19, GB1015, doi:10.1029/2003GB002199, 2005.

Kucharik, C. J.: Evaluation of a process-based agro-ecosystem model (Agro-IBIS) across the US corn belt: simulations of the interannual variability in maize yield, Earth Interact., 7, 1-33, 2003.

Kutsch, W., Aubinet, M., Buchmann, N., Smith, P., Osborne, B., Eugster, W., Wattenbach, M., Schrumpf, M., Schulze, E., and Tomelleri, E.: The net biome production of full crop rotations in Europe, Agr. Ecosyst. Environ., 139, 336-345, 2010.

Licker, R., Johnston, M., Foley, J. A., Barford, C., Kucharik, C. J., Monfreda, C., and Ramankutty, N.: Mind the gap: how do climate and agricultural management explain the "yield gap" of croplands around the world?, Global Ecol. Biogeogr., 19, 769782, 2010.

Loarie, S. R., Lobell, D. B., Asner, G. P., Mu, Q., and Field, C. B.: Direct impacts on local climate of sugar-cane expansion in Brazil, Nature Climate Change, 1, 105-109, 2011.

Lobell, D., Bala, G., and Duffy, P.: Biogeophysical impacts of cropland management changes on climate, Geophys. Res. Lett., 33, L06708, doi:10.1029/2005GL025492, 2006.

Lobell, D. B. and Field, C. B.: Global scale climate-crop yield relationships and the impacts of recent warming, Environ. Res. Lett., 2, 014002, doi:10.1088/1748-9326/2/1/014002, 2007. 
Lobell, D. B., Schlenker, W., and Costa-Roberts, J.: Climate trends and global crop production since 1980, Science, 333, 616-620, 2011.

Moffat, A. M., Papale, D., Reichstein, M., Hollinger, D. Y., Richardson, A. D., Barr, A. G., Beckstein, C., Braswell, B. H., Churkina, G., and Desai, A. R.: Comprehensive comparison of gap-filling techniques for eddy covariance net carbon fluxes, Agr. Forest Meteorol., 147, 209-232, 2007.

Müller, C.: Agriculture: Harvesting from uncertainties, Nature Climate Change, 1, 253-254, 2011.

Mueller, N. D., Gerber, J. S., Johnston, M., Ray, D. K., Ramankutty, N., and Foley, J. A.: Closing yield gaps through nutrient and water management, Nature, 490, 254-257, 2012.

Osborne, T., Slingo, J., Lawrence, D., and Wheeler, T.: Examining the interaction of growing crops with local climate using a coupled crop-climate model, J. Climate, 22, 1393-1411, 2009.

Papale, D., Reichstein, M., Aubinet, M., Canfora, E., Bernhofer, C., Kutsch, W., Longdoz, B., Rambal, S., Valentini, R., Vesala, T., and Yakir, D.: Towards a standardized processing of Net Ecosystem Exchange measured with eddy covariance technique: algorithms and uncertainty estimation, Biogeosciences, 3, 571-583, doi:10.5194/bg-3-571-2006, 2006.

Parry, M., Rosenzweig, C., and Livermore, M.: Climate change, global food supply and risk of hunger, Philos. T. R. Soc. B, 360, 2125-2138, 2005.

Pitman, A., de Noblet-Ducoudré, N., Cruz, F., Davin, E., Bonan, G., Brovkin, V., Claussen, M., Delire, C., Ganzeveld, L., and Gayler, V.: Uncertainties in climate responses to past land cover change: First results from the LUCID intercomparison study, Geophys. Res. Lett., 36, L14814, doi:10.1029/2009GL039076, 2009.

Prescher, A.-K., Grünwald, T., and Bernhofer, C.: Land use regulates carbon budgets in eastern Germany: From NEE to NBP, Agr. Forest Meteorol., 150, 1016-1025, 2010.

Ramankutty, N. and Foley, J. A.: Characterizing patterns of global land use: An analysis of global croplands data, Global Biogeochem. Cy., 12, 667-685, 1998.

Ramankutty, N., Foley, J. A., and Olejniczak, N. J.: People on the land: Changes in global population and croplands during the 20th century, AMBIO: A Journal of the Human Environment, 31, 251-257, 2002.

Reichstein, M., Falge, E., Baldocchi, D., Papale, D., Aubinet, M., Berbigier, P., Bernhofer, C., Buchmann, N., Gilmanov, T., and Granier, A.: On the separation of net ecosystem exchange into assimilation and ecosystem respiration: review and improved algorithm, Glob. Change Biol., 11, 1424-1439, 2005.

Rosenzweig, C. and Parry, M. L.: Potential impact of climate change on world food supply, Nature, 367, 133-138, 1994.

Rosenzweig, C., Elliott, J., Deryng, D., Ruane, A. C., Müller, C., Arneth, A., Boote, K. J., Folberth, C., Glotter, M., and Khabarov, N.: Assessing agricultural risks of climate change in the $21 \mathrm{st}$ century in a global gridded crop model intercomparison, P. Natl. Acad. Sci. USA, 111, 3268-3273, 2014.
Sacks, W. J. and Kucharik, C. J.: Crop management and phenology trends in the US Corn Belt: Impacts on yields, evapotranspiration and energy balance, Agr. Forest Meteorol., 151, 882-894, 2011.

Sellers, W. D.: Physical Climatology, University of Chicago Press, Chicago, IL, 1965, 272p.

Stocker, T., Qin, D., Plattner, G., Tignor, M., Allen, S., Boschung, J., Nauels, A., Xia, Y., Bex, V., and Midgley, P.: IPCC, 2013: Climate Change 2013: The Physical Science Basis. Contribution of Working Group I to the Fifth Assessment Report of the Intergovernmental Panel on Climate Change. Cambridge Univ Press, Cambridge, United Kingdom and New York, NY, USA, 2013.

Trenberth, K. E., Dai, A., van der Schrier, G., Jones, P. D., Barichivich, J., Briffa, K. R., and Sheffield, J.: Global warming and changes in drought, Nature Climate Change, 4, 17-22, 2014.

Tubiello, F. N., Soussana, J.-F., and Howden, S. M.: Crop and pasture response to climate change, P. Natl. Acad. Sci. USA, 104, 19686-19690, 2007.

Twine, T. E., Kustas, W., Norman, J., Cook, D., Houser, P., Meyers, T., Prueger, J., Starks, P., and Wesely, M.: Correcting eddycovariance flux underestimates over a grassland, Agr. Forest Meteorol., 103, 279-300, 2000.

Valade, A., Ciais, P., Vuichard, N., Viovy, N., Caubel, A., Huth, N., Marin, F., and Martiné, J.-F.: Modeling sugarcane yield with a process-based model from site to continental scale: uncertainties arising from model structure and parameter values, Geosci. Model Dev., 7, 1225-1245, doi:10.5194/gmd-7-12252014, 2014.

Van den Hoof, C., Hanert, E., and Vidale, P. L.: Simulating dynamic crop growth with an adapted land surface model - JULESSUCROS: Model development and validation, Agr. Forest Meteorol., 151, 137-153, 2011.

Vitale, L., Di Tommasi, P., Arena, C., Fierro, A., Virzo De Santo, A., and Magliulo, V.: Effects of water stress on gas exchange of field grown Zea mays L. in Southern Italy: an analysis at canopy and leaf level, Acta Physiol. Plant., 29, 317-326, 2007.

Vuichard, N., Ciais, P., Belelli, L., Smith, P., and Valentini, R.: Carbon sequestration due to the abandonment of agriculture in the former USSR since 1990, Global Biogeochem. Cy., 22, GB4018, doi:10.1029/2008GB003212, 2008.

Willmott, C. J., Ackleson, S. G., Davis, R. E., Feddema, J. J., Klink, K. M., Legates, D. R., O’Donnell, J., and Rowe, C. M.: Statistics for the evaluation and comparison of models, J. Geophys. Res.Oceans, 90, 8995-9005, 1985. 